\title{
Characterization of Off-the-Shelf Hardware for Transcutaneous Power and Data Transmission
}

\author{
N.H. Marks, E.A. Cheever* \\ Department of Engineering \\ Swarthmore College \\ 500 College Avenue \\ Swarthmore, PA 19081
}

\begin{abstract}
There are many applications in biomedicine in which transcutaneous transmission of information and/or power is necessary. Typically, a custom-made receiver/transmitter pair must be designed and built to meet specific design requirements. This paper describes the testing and characterization of off-theshelf hardware to perform these functions. The increasing ubiquity of RFID (Radio Frequency IDentification) and energy harvesting applications has lead to a concomitant increase in the availability of hardware and software to support them. In this paper the communication and power transfer capabilities of an inexpensive (<\$200) RF evaluation kit from Texas Instruments are explored. The kit includes both a transmitter/base station and a small $(2 \mathrm{~cm}$ by $3 \mathrm{~cm}$ ) board with a receiving coil, RFID decoder and microcontroller. Communication is possible at distances up to $6.5 \mathrm{~cm}$ (depending on the location and orientation of the receiver relative to transmitter) and power transmission up to $0.5 \mathrm{~mW}$ is achieved at distances as far as $1 \mathrm{~cm}$.
\end{abstract}

\section{INTRODUCTION}

Implanted medical devices have many applications including neural and muscular stimulation, hearing aids and cochlear prosthetics, cardiac pacemaking and defibrillation, chemical sensing, and others [1]. Typically custom-made receiver/transmitter hardware must be designed and built to meet specific design requirements (e.g., for bandwidth and power) [2, $3,4]$. It is possible to use batteries or various energy harvesting schemes to supply the necessary power, but a combined power/communication system can simplify system design $[5,6]$. Moreover, the increasing use of RFID, often combined with energy transfer, has increased the availability of commercially manufactured options. In this paper we characterize the performance of an inexpensive $(<\$ 200)$ evaluation kit from Texas Instruments [7]. Though not certified for use in humans, such a system could be used in animal-based studies.

The kit contains a base station and a remote circuit board with TMS37157 passive low-frequency RFID transponder connected to a low power 16 bit MSP430F2274 microcontroller. The base station has a $1.95 \mathrm{~cm}$ radius transponder antenna that operates at a frequency of $134.2 \mathrm{kHz}$; the remote board has a $2.66 \mathrm{mH}$ coil that is $1.1 \mathrm{~cm}$ by $0.35 \mathrm{~cm}$. At these frequencies the coupling between the base station and the transponder is due to coupling of the magnetic field between the base station and the remote board. This makes the system amenable to applications involving implantation because magnetic fields penetrate tissue well at these frequencies [8].

\footnotetext{
* To whom correspondence should be sent.
}

\section{PROCEDURE}

Two types of measurements were made to characterize the system. First, range of communication was established by moving the remote unit relative to the transmitter. These tests were done at different relative orientations of the base station transmitter coil and the remote unit receiving coil. Subsequent measurements determined the efficacy of power transmission between the transmitter and receiver.

In both cases the position of the base station remained fixed. The receiver location was manipulated with a 3-axis steppermotor positioning system with an accuracy of $0.005 \mathrm{~mm}$.

To test the physical range over which reliable communication was possible, a "zero" position was established by placing the receiving coil as closely as possible to the center line and plane of the transmitter coil. The remote unit was then moved in 0.5 $\mathrm{cm}$ increments through a volume in front of the transmitter coil large enough that it extended beyond the distance in all three dimensions where communication was lost. At each location, data was written from the transmitter to the remote unit and then read back to ensure viable communication. This test was repeated five times at each location. Because of built-in cyclical redundancy checks, erroneous data was never returned. Instead, the write-read transaction detected incorrect data and reported that communication failed.

To measure power transmission capabilities, the remote board was programmed to charge a $10 \mu \mathrm{F}$ capacitor. At close range, the capacitor could charge to slightly more than $3.0 \mathrm{~V}$ We estimated the power transfer by finding the time, $\Delta \mathrm{t}$, taken for the voltage across the capacitor to go from 1.4 to $2.6 \mathrm{~V}(\Delta \mathrm{v}=1.2$ V). The power was then calculated as

$$
\text { power }=\mathrm{v}_{\text {average }} \cdot \mathrm{i}_{\text {charge }}=2 \cdot \mathrm{C} \frac{\Delta \mathrm{v}}{\Delta \mathrm{t}}
$$

If the coil separation was sufficiently large that the final voltage was less than $3.0 \mathrm{~V}$ the charge power was recorded as zero. Again, measurements were made at $0.5 \mathrm{~cm}$ intervals.

\section{RESULTS}

Fig. 1 shows a surface plot of the volume in which communication was successful for all five write-read cycles with the axes of both the transmit and receive coils along the $\mathrm{z}$ axis. The location of the base-station coil is shown as a ring on the $x-y$ plane. 


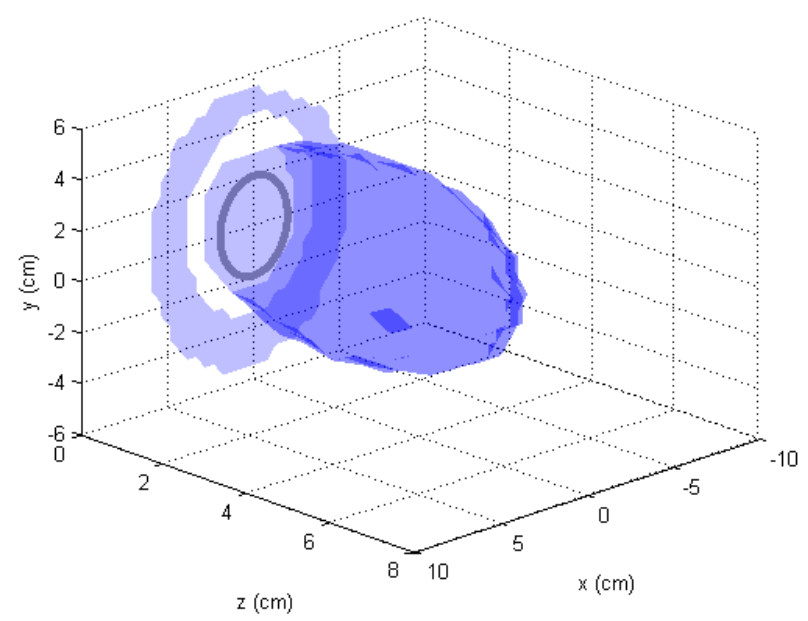

Fig. 1. Surface showing successful communication between base station and receiver; coils aligned along z-axis.

The surface shows radial symmetry along the z-axis with the largest distance being exactly upon the z-axis. The maximum distance with successful communication is $6.5 \mathrm{~cm}$. The main lobe has a width of about $8 \mathrm{~cm}$ at its widest point. The shape of the surface is as expected given the known magnetic field of a coil of wire [9].

If the receiving coil is turned $90^{\circ}$ so it is along the $\mathrm{x}$-axis, the surface develops two lobes, as expected. The maximum depth at which communication is possible is reduced to less than $5 \mathrm{~cm}$; this is displayed in Fig. 2.

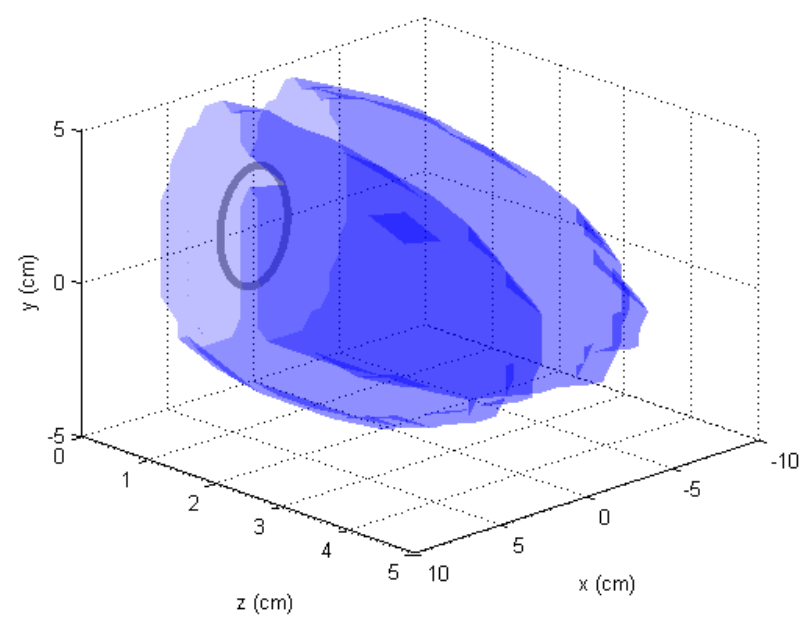

Fig. 2. Surface showing successful communication with receiver coil aligned along $\mathrm{x}$-axis.

Fig. 3 shows a contour plot of the power transmitted with the coils aligned. The coil was moved along the $\mathrm{x}-\mathrm{z}$ plane $(\mathrm{y}=0)$. The contour levels are the measured power, in $\mathrm{mW}$. The maximum power transfer was less than $1 \mathrm{~mW}$, and measureable power extended less than $3 \mathrm{~cm}$ from the base station.

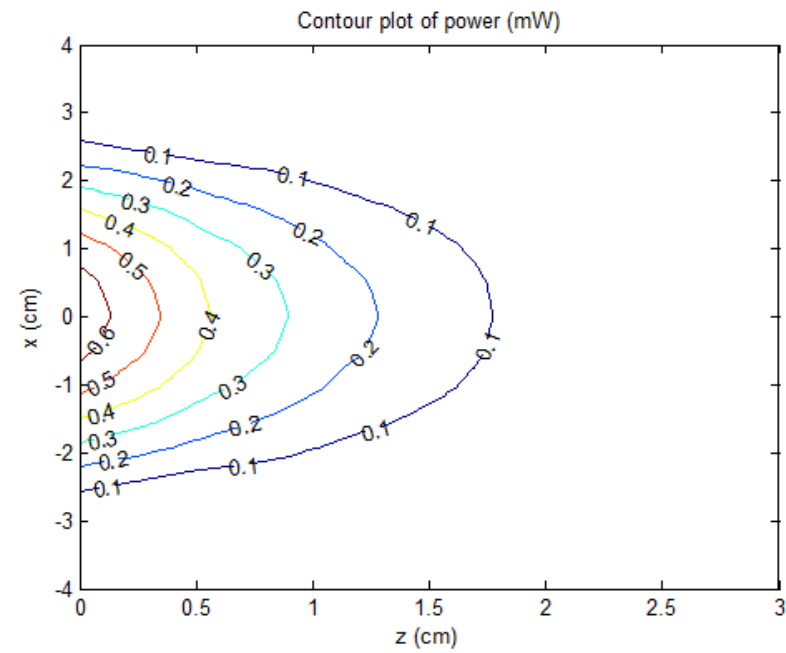

Fig. 3. Contour plot showing received power on $\mathrm{x}-\mathrm{z}$ plane.

\section{DISCUSSION}

An off-the-shelf Texas Instruments RFID/power transmission system was characterized. Communication was possible at distances up to $6.5 \mathrm{~cm}$ when the axes of the coils were aligned. Misalignment of the coils reduced this distance. Effective power transmission was limited to distance of about $2 \mathrm{~cm}$ with maximum power transfer less than $1 \mathrm{~mW}$. This would be ineffective for applications requiring battery charging or active muscle stimulation. However, it is sufficient for sensing application and some applications that require direct neuronal stimulation [5, 6]. Modifications to the system, such as changing the receiving coil, may increase these capabilities.

\section{ACKNOWLEDGMENTS}

This work was supported by the HHMI grant to Swarthmore College that supports undergraduate summer research.

\section{REFERENCES}

[1] R. Bashirullah, "Wireless Implants," IEEE Microwave Magazine, vol. 11:7, 2010, pp. 14-23.

[2] J. Van Ham and R. Puers, "A Power and Data Front-End IC for Biomedical Monitoring Systems," Sensors and Actuators A, Vol. 147, 2008, pp. 641648.

[3] M. Ghovanloo and S. Atluri, "An Integrated Full-Wave CMOS Rectifier with Built-In Back Telemetry for RFID and Implantable Biomedical Applications," IEEE Trans. Circuits Syst. I, Reg. Papers, Vol. 55:10, 2008, pp. $2605-13$

[4] C. Sauer, M. Stanacevic, G Cauwenberghs and N. Thakor, "Power Harvesting and Telemetry in CMOS for Implanted Devices," IEEE Trans. Circuits Syst. I, Reg. Papers, Vol. 52:12, 2005, pp. 2605-13.

[5] M. Rasouli and L.S.J. Phee, "Energy Sources and Their Development for Application in Medical Devices," Expert Rev. Med. Devices, Vol. 7:75, 2010, pp. 693-709.

[6] A.P. Chandrakasan, N. Verma and D.C. Daley, "Ultralow-Power Electronics for Biomedical Applications," Annu. Rev. Biomed. Eng., Vol. 10, 2008, pp. 247-74

[7] "EZ430-TMS37157: PaLFI, Passive Low Frequency Evaluation Kit TMS37157," http://focus.ti.com/docs/toolsw/folders/print/ez430tms37157.html, accessed Jan 21, 2011.

[8] K.R. Foster and H.P. Schwan, "Dielectric Properties of Tissues and Biological Materials: A Critical Review," CRC Crit. Rev. Bio. Eng., vol 17:1, 1989, pp 25-104.

[9] "Off-Axis Field of a Current Loop," http://www.netdenizen.com/ emagnettest/offaxis/?offaxisloop, accessed Jan. 25, 2011. 